\title{
Forensic DNA databases
}

\author{
Francisco Corte-Real ${ }^{\mathrm{a}, \mathrm{b}, *}$ \\ ${ }^{\mathrm{a}}$ National Institute of Legal Medicine, University of Coimbra, Portugal \\ ${ }^{\mathrm{b}}$ Faculty of Medicine, University of Coimbra, Portugal
}

\begin{abstract}
Genetic databases have been created in several countries: the United Kingdom was the first European country to have, in 1995, a DNA database. Subsequently, the Netherlands and Austria (1997), Germany (1998), Finland and Norway (1999) and many others have introduced or are preparing databases.

Different national legal systems have conditioned the DNA databases and so there is a great heterogeneity between countries. The criteria for an entry of a DNA profile, the criteria for a removal, the criteria for a search, etc., can lead to very distinct databases.
\end{abstract}

(C) 2004 Elsevier Ireland Ltd. All rights reserved.

Keywords: Forensic; DNA; Databases

\section{Introduction}

Genetics as developed last decade as no other scientific field. In forensics, the criminal genetic studies have become a usual tool, due to the possibility of very small biological stains identification. The DNA amplification by the polimerase chain reaction (PCR) technique supported very strongly the development of forensic genetics, specially the criminalistics.

However, even if we can identify the DNA profile of a bloodstain left by the criminal or a swab with semen from the sexual crime scene, when there is no DNA database several cases have no conclusion.

In many countries, like Portugal, there are laboratories with technological and human capacities to perform forensic genetic investigations but because of a lack of a suspect, frequently no useful information is sent to the court. Considering all criminal genetic investigations required to the Portuguese National Institute of Legal Medicine, in about one fifth of the cases no suspect profile was presented for comparison. With a DNA database there are some possibi-

\footnotetext{
* Tel.: +351 239 854230; fax: +351 239836470 .

E-mail address: fcortereal@inml.mj.pt.
}

lities of identifying the suspect (if he had been previously included in the database) or to say that the same suspect had already been involved in other crime(s).

\section{Forensic DNA databases approaches}

The Council Resolution of 9 June 1997 on the exchange of DNA analysis results invited Member States to consider establishing national DNA databases in accordance with the same standards and in a compatible manner. This is an important issue to be followed as the mobility of persons between European countries has become easy in the last decade and it is frequent to catch a person in a country responsible for a crime committed in another country. Using the same technology, quality requirements, proficiency tests and all the markers included in the European standard set (ESS) adopted by the Council Resolution of 25 June 2001 (D3S1358, vWA, D8S1179, D21S11, D18S51, HumTH01, FGA), the need for a pan-European DNA database can be replaced by a strong collaboration and change of informations between the national authorities.

Some countries include in the DNA databases only the convicted offenders by serious crimes, like sexual crimes 
and crimes against life, or include also robbery, theft or blackmail $[1,2]$. In other ones, the criteria of entry depend on the corresponding number of years of imprisonment. Serious crimes with strong possibility of leaving biological material and with eventual repetitive characteristics are usually the first to be included but very strong results have been achieved with minor offences. The experience with some databases seams to indicate that before the commitment of a serious crime, some suspects have already been involved in minor offences. This fact associated to the repetitive motif of some serious crimes can support the importance of DNA databases not only to the criminal investigation but also to the prevention of crime, mainly if there are large entry criteria.

The storage of genetic information is an important question too and it is possible to choose between the storage of only the DNA profiles or also the biological samples. The critics of the DNA databases are fearful of the samples misuse and the possibility that insurance companies can have access to biological samples and informations about the characteristics or pathologies of the owners. In spite of all the cares that must be considered when dealing with this question, the problem is not specific to the DNA databases but to the forensic DNA analysis in general. In several countries without DNA databases yet there are Institutes of Legal Medicine or Police Labs with hundreds or thousands of biological samples, from paternity investigations or criminal genetic identifications, where the fearful of the samples misuse is not equally considered. These labs are under the obligation of using the samples only for the purposes that justified their collection - Recommendation no. R (92) 1, from 10 February 1992. And also the Council Resolutions of 9 June 1997 and 25 June 2001 limit the use of DNA to the "non-coding part", to "chromosome zones containing no genetic expression".

If we want to avoid the fears related to the misuse of samples obtained from identified persons, these samples can be immediately destroyed after the profile is determined. However, when there is a sporadic hit between a new profile and another one belonging to the database, reanalysis with a larger number of markers should be performed. Or if the scientific community decide to perform, in the future, other (or different) markers, the presence of the samples would be essential. The previous destruction of samples will consequently demand new samples to repeat the analysis, with the inconvenients of new collections. Nevertheless, new collections will provide a new complementary control, confirming all the steps from the beginning.

To prevent incorrect use of the samples, the storage can be codified and it can be established a separate register for personal records outside the laboratory and only in some occasions (by court order for instance) a search should be made. It is important to assure equality of arms to the defence, having similar access to this kind of proof, as it was established by the European Council Recommendation no. R (92) 1.

Depending on the countries, the removal has been established after a defined number of years $(5,10,15,20 \ldots)$ or the profiles are permanently present in the database and are removed only those belonging to acquitted suspects.

With the aim of individual identification by comparison between unidentified samples or bodies and the biologic material from missing persons or from their relatives, civil DNA databases should also be created separately from the criminal databases. The entry criteria should consider the relatives consent to include their own profiles (removable voluntarily at any time) and the definitive removal should be associated to the respective identification.

\section{References}

[1] M. Guillén, M.V. Lareu, C. Pestoni, A. Salas, A. Carracedo, Ethical-legal problems of DNA databases in criminal investigation, J. Med. Ethics 26 (4) (2000) 266-271.

[2] P.M. Schneider, P.D. Martin, Criminal DNA databases: the European situation, Forensic Sci. Int. 119 (2001) 232-238. 